\title{
Reglamento de 1769 de la Iglesia Católica Romana POR EKATERINA II (CATALINA II). DOCUMENTO JURÍDiCO FUNDAMENTAL DE LA LEGISLACIÓN DE LA IGLESIA CATÓLICA EN RUSIA IMPERIAL
}

[The ukase of 1769 of Yekaterina II (Catherine II) on the Roman Catholic Church. A fundamental legal document of the Catholic Church legislation in Imperial Russia]

\author{
Yulia Poliakova (Devonisskaya-Pistolyaka)* \\ Universidad Técnica Federico Santa María, Valparaíso, Chile
}

\section{RESUMEN}

El objetivo de este trabajo es presentar a la emperatriz Ekaterina II (Catalina II), como una estadista y legisladora poco conocida en América Latina. Últimamente se han publicados dos volúmenes de mil páginas cada uno, con sus actas y documentos legislativos ${ }^{1}$. Analizamos el documento \# 148 del Capítulo 3.2 Sobre religiones no ortodoxas, en el volumen I bajo el título de Reglamento dado a la Iglesia Católica Romana de San Petersburgo, generado como consecuencia de una queja de la comunidad católica multinacional, a la conducta de curia romana, de no atender

\section{AbSTRaCt}

The aim of this work is to introduce Empress Catherine II like a state woman and legislator little known in Latin America. Recently two volumes with one thousands page each have been published. We analize the document $\mathrm{N}^{\circ} 148$ from chapter 3.2 "On non-orthodox religions", in the volume 1, under the title of "Regulation given to the Roman Catholic Church of Saint Petersburgh". This was generated as a consequence of a complaint by the multinational catholic Community to the Roman Clergy for not considering the believers' petitions, for not stopping

ReCiBIDO el 28 de abril y ACEPTADO el 30 de junio de 2017

* Magíster en Física por la Universidad Estatal de Moscú Lomonósov, Magíster en Historia por la Universidad de Valparaíso, Chile. Profesora de la Universidad Técnica Santa María, Valparaíso, Chile. Dirección postal: Avenida España 1680, Valparaíso, Chile, Universidad Santa María, correo: yulia.poliakova@usm.cl

1 Чистяков, О.И., Новицкая, Т.Е. Законодательство Екатерины II. Т 2. Москва. Юридическая литература, 2000. Chistyakov, O.I., Novitskaya, T. E. Legislación de EkaterinaII, II, (Moscú, Ed. Literatura Jurídica, 2000). Traducción libre del título ruso por autora. 
las solicitudes de los fieles, de no detener los abusos financieros de los sacerdotes contratados. Ekaterina II legisla sobre el funcionamiento de la iglesia a favor de los feligreses sin tocar asuntos religiosos. Entre los principales ítems estaba el control de los bienes por la comunidad, que evitaba su manejo unilateral por el párroco. La comunicación con Roma fue permitida solamente para cuestiones espirituales.

\section{Palabras Clave}

Emperatriz Ekaterina II - Queja de la comunidad católica multinacional - Curia romana - Reglamento de 1769. the financial abuses by the hired priests. Catherine II legislates on the performance of the church in favor of the believers without touching religious matters. Among the main items there was the control of the possessions by the Community which prevented the unilateral administrations by Parish priest. The communication with Rome was only allowed for spiritual matters

KeYwORDS

Empress Catherine II - Complaint of the multinational catholic community Roman Clergy - Regulation of 1769.

\section{INTRODUCCIÓN}

Es bien conocido que antes del reinado del zar Pedro I el Grande ${ }^{2}$, la situación espiritual de los extranjeros católicos contratados al servicio de la Santa Rusia ${ }^{3}$ era precaria. No estaba permitida la construcción de las iglesias, ni las misiones. A veces los clérigos regulares, que llegaron a Rusia como profesores de los niños extranjeros, atendieron capillas domésticas. Con Pedro I, -quien convirtió a un país medieval, aislado, en un Estado moderno y poderoso- se inicia un período de tolerancia religiosa en Rusia, el que no sólo se debe a una necesidad política, sino que estuvo basado sobre los principios legales del Estado. La tolerancia por primera vez fue declarada en su Manifiesto ${ }^{4}$ del 16 de abril de 1702, destinado a ser publicado en toda Europa para atraer profesionales en distintas áreas y oficios: ingenieros, militares, marinos, constructores de toda índole, arquitectos, científicos, artistas, técnicos y artesanos, entre otros, para crear así una Rusia moderna. En virtud de esta libertad, a los extranjeros se les concedió el derecho a construir iglesias en cada ciudad, dondequiera que moraran. Pero las leyes antiguas, que castigaban severamente a todos los no ortodoxos que difundieran una doctrina religiosa ajena entre los rusos, se mantuvieron con toda su fuerza. En 1705, luego de la alianza con el rey polaco Augusto II el Fuerte, durante la Gran Guerra Nórdica contra Suecia, fue publicado un Manifiesto dedicado específicamente a la libertad religiosa de los católicos, los que obtienen el mismo derecho de

2 Piotr (Alekseevich-hijo de Alekséy) Romanov el Grande (Moscú, 9 de junio de 1672 San Petersburgo, 8 de febrero de 1725), zar desde 1682 con su hermano Iván, autócrata de Rusia 1696-1725.

3 Así llamaron los rusos a su patria hasta el siglo XX.

${ }^{4}$ Manifiesto del monarca era un documento público de alta importancia dedicado a toda la población donde se pregona la voluntad del monarca, es distinto de un Ukaz (decreto) dedicado a personas o instituciones que tienen que ejecutarlo. 
construcción de sus templos en los lugares de residencia, de acuerdo al principio general del Manifiesto de 1702. Por el edicto del 3 de marzo 1719, los extranjeros contratados por el Estado con residencia temporal podían confesar libremente su religión en cualquier lugar de Rusia 5 .

Los primeros pasos de la emperatriz Ekaterina II la Grande, coronada en el año 1762, fueron proseguir la misma política de Pedro I, en el fortalecimiento y en el adelanto económico-militar del país. Ella, además del desarrollo ingenieril, estaba muy interesada en poblar grandes territorios eriazos y no cultivados. Por esto puso en el programa estatal de reclutamiento en Europa, además de los profesionales y de la mano de obra calificada, la invitación especial a los campesinos alemanes sin importar sus creencias, cosa imposible sin una libertad religiosa declarada a los nuevos residentes de Rusia. Durante los primeros diez años del reinado de Ekaterina II, la comunidad católica creció aproximadamente desde 2 mil a 20 mil creyentes dentro de una población rusa de 23 millones ${ }^{6}$.

En los años de Pedro I, cuando el número de católicos en el Imperio no era grande, no había necesidad de instrucciones especiales para reglas de funcionamiento de la Iglesia católica. La regulación en cuestión se limitaba a las actas que se referían a una subdivisión territorial de los creyentes. Pedro I puso a los católicos bajo vigilancia permanente del Santo Sínodo ${ }^{7}$ y el gobierno. A los clérigos regulares permitidos para el servicio religioso, les fue prohibida cualquier propaganda religiosa y la conversión de los rusos. A pesar que Pedro I había invitado a los jesuitas en 1717 como profesores de los niños católicos, desde el año 1719 prohibió su entrada a Rusia por estar involucrados en el caso de su hijo-heredero Alekséy $^{8}$, lo que fue respetado por Ekaterina II.

La construcción de los templos en las ciudades fue costeada por los feligreses, igual que el servicio del clero contratado desde Roma. Para los colonos del Volga, la emperatriz hizo un préstamo monetario de 10 años con el fin atender las necesidades en el servicio religioso tanto para los católicos, como para los protestantes?.

Pero, como escribe la destacada historiadora Isabel de Madariaga, "parece que las comunidades católicas no tuvieron suerte con los sacerdotes enviados de la Santa Sede. Habitualmente hubo conflictos y peleas entre el clero y los parroquianos y entre los clérigos de diferentes órdenes, la mayoría de las veces por asuntos de

${ }^{5}$ БулавинаМ.А., Правовоеположениекатолическойцеркви в России в XVIII веке.Диссертация на соискание ученой степени кандидата юридических наук. Ставрапольский государственный университет, 2008. Ctp.14-15. Bulavina, M.A., Situación legal de la Iglesia católica en el siglo XVIII (Tesis Ph.D en Derecho, 2008), pp.14-15. Traducción libre del título ruso por la autora.

${ }^{6}$ Рубакин, Н.А. Россия в иифрах. Страна, народ, сословия, классы. Вестник знания. СПБ. 1912. RubÁkin, N.A. Rusia en cifras. País, pueblo, niveles sociales, clases. En noticias de conocimiento (San Petersburgo, 1912). Traducción libre del título ruso por la autora.

7 Santo Sínodo fue una institución gubernamental introducida por Pedro I el Grande que reemplazaba al Patriarca.

${ }^{8}$ Alekséy casado con una princesa alemana fue gran opositor a las reformas suyas e involucrado en la preparación del golpe estatal diseñado en la Corte de Viena por los jesuitas austríacos. En consecuencia los jesuitas fueron expulsados de Rusia Imperial en 1719.

9 Bulavina, M.A.,cit. (n. 5), p. 23 
dinero y bienes de la comunidad. Los parroquianos buscaron justicia y defensa del gobierno ruso. El escándalo más grande surgió en los primeros años del reinado de Ekaterina, en $1766 "{ }^{\prime \prime}$. Tras este escándalo el gobierno recibe una queja de los feligreses de la parroquia multinacional de residentes de San Petersburgo. Pidieron defender sus intereses ante Roma, que les enviaba sacerdotes -cuyo ministerio, estadía y traslados los pagaba la comunidad católica en su totalidad- que no conocían los idiomas de todos los parroquianos, es decir, alemán, polaco, francés e italiano. Además se quejaron de que el clero, no utilizaba de buena forma los recursos de la Iglesia, "habia producido grandes deudas a los parroquianos, tanto que para edificación de iglesia no quedó dinero"11.

La emperatriz asumió el problema y ordenó a la Comisión gubernamental elaborar el proyecto de reglamento para la Iglesia católica de San Petersburgo. El 6 de noviembre de 1766 salió un Ukaz (decreto) "Sobre la composición del Reglamento de la Iglesia Católica Romana de San Petersburgo". El reglamento hubo de ser cumplido por sus parroquianos y el clero al firmar Ekaterina II su redacción final. Este documento obtiene el rango de Imennoy Ukaz (decreto supremo), es decir, firmado "de puño y letra del monarca".

La Comisión gubernamental analizó el problema de la siguiente manera: i) desde la aparición de la Iglesia católica romana en el imperio, no se emitió ninguna ley relevante sobre la invitación a los sacerdotes católicos para las parroquias multinacionales y multilingües; ii) el Estado nunca ha puesto ni publicado reglas especiales que regulasen las obligaciones de los clérigos y los parroquianos en asuntos económicos y ritos de la iglesia; iii) en el Imperio Ruso no existe la instancia judicial, que puede examinar quejas semejantes, por eso el clero, sin temer al castigo, se apropiaba de los fondos recogidos por la parroquia.

Los legisladores encargados de solucionar el problema llegaron a la conclusión de que: "si en nuestro Imperio hay una iglesia para la gente de la fe católica romana, y como estas personas son nuestros ciudadanos y deben pagar y dar el dinero para la iglesia, entonces la cantidad obtenida de ellos debería ser gastada según su voluntady el deseo, y asi lo será siempre bajo la protección de nuestras leyes".

En el proyecto del reglamento de la Iglesia católica de San Petersburgo, también se incluyeron reglas para la iglesia de Moscú y para las iglesias de las colonias de los emigrantes católicos en la cuenca del Volga. Para evitar en el futuro malentendidos similares, la emperatriz después de revisar y firmar el documento ordenó publicarlo en 12 de febrero 1769 como Reglamento imperial para iglesias romanas existentes en Rusia sin consulta con ninguna autoridad católica. Dicho documento declara la intención de Ekaterina II de no meterse a los asuntos del dogma y de las normas religiosas de la Iglesia católica apostólica romana.

10 Мадарьяга, Исабель де, Россия в эпоху Екатерины Великой (Москва, 2002), C. 815-816. (trad.rus.) Madariaga, Isabel, Rusia in the Age of Catherine the Great (London, 1989). Rusia en los tiempos de Ekaterina la Grande (Moscú, 2002), pp. 815-816. Traducción libre del título ruso por la autora.

11 Ver Anexo 1. 


\section{ANÁLISIS DEL REGLAMENTO IMPERIAL PARA IGLESIAS \\ ROMANAS ${ }^{12}$ EXISTENTES EN RUSIA}

Este documento está compuesto de la Introducción, once capítulos, con 51 párrafos, y Postscriptum:

Introducción. Capítulos: 1. Sobre los pastores de la Iglesia Romana en general. 2. Relativo al padre prepósito o al jefe en particular. 3. Relativo al llamado de los pastores, de su juramento e incorporación a la comunidad de destino. 4. De la elección e instalación del prepósito en la iglesia, en San Petersburgo 5. De los síndicos de la iglesia. 6. Sobre los ingresos parroquiales y de las obligaciones de los sindicos. 7. De los informes finales y la desvinculación de los sindicos. 8. Sobre el juzgado bajo cuya jurisdicción debe encontrarse la Iglesia Romana. 9. Sobre el despido de los sacerdotes. 10. Sobre eclesiásticos inscritos en la Iglesia Romana en Moscú. 11. Sobre asignación de los clérigos a las colonias del Volga. Postscriptum.

\section{Introducción del reglamento}

Incluye la historia de la aparición del documento, la queja de los parroquianos de la iglesia de San Petersburgo, el análisis del problema, la declaración de Ekaterina de no meterse en los asuntos del dogma, el ordenamiento de normas a seguir de acuerdo a la numeración puesta por la monarca.

La emperatriz y autócrata de toda Rusia dice que a los clérigos romanos se había dado el permiso para servir a los católicos residentes en las iglesias romanas por sus antecesores: Pedro I y Anna Ivánova ${ }^{13}$; que en la comunidad católica de San Petersburgo surgió un gran desacuerdo entre los parroquianos, ciudadanos rusos, católicos de origen extranjero y los eclesiásticos enviados desde Roma; que los parroquianos sin saber dónde buscar la justicia pidieron a la monarca resolver tres problemas: i) pedir a Santa Sede contratar para su iglesia en San Petersburgo clérigos extranjeros de buen nivel con conocimiento de idiomas de los feligreses, provechosos y eficientes para el servicio en Rusia; ii) que puedan siempre elegir, ellos mismos, con la partida de un prepósito u otro clérigo, otro sacerdote para su reemplazo entre los que se encuentren en San Petersburgo que sea más experimentado y de mayores méritos sin importar su nación, porque los feligreses siempre saben mejor que los de la congregación apreciar al elegido en su justo valor. Que el elegido para el servicio religioso sería confirmado en su puesto por la Congregación de Propagación de la Fe Romana; iii) que los parroquianos puedan elegir entre sí los síndicos de la iglesia, los que junto con el prepósito mayor tengan el poder pleno de mantener la iglesia y de aumentar los ingresos tanto con colectas recogidas de los feligreses, como por arriendo de las edificaciones anexas para sostener la escuela parroquial y para otros gastos de la iglesia. Con las deudas permitidas unánimemente por los parroquianos, ellos mismos se comprometen a su pago y piden que no sea aceptado que los prepósitos tomen préstamos en

12 En documentos de Ekaterina la Iglesia católica se llama la Iglesia Romana.

13 Emperatriz Anna (Ivánova-hija de Iván) Románova (Moscú, 28 de enero 1693 - San Petersburgo, 17 de octubre de 1740). Sobrina de Pedro I. La emperatriz de Rusia durante $1730-1740$. 
dinero con su firma personal sin avisar ni pedir permiso a toda la comunidad parroquial; ni tampoco que abandonen el país sin rendir las cuentas y dejando la carga del pago sobre los feligreses.

\section{La respuesta a los católicos demandantes}

La emperatriz, respondiendo a los súbditos católicos puso condiciones a la aceptación de los prepósitos y otros sacerdotes llegados a Rusia (conocimiento idiomas de los parroquianos, pertenencia a las órdenes permitidas por Pedro I), prohibiendo estrictamente la conversión de los rusos a la fe católica. Ella aumentó la cantidad de clérigos y el tiempo de su estadía en Rusia para mejorar el servicio religioso y reducir los gastos de feligreses por traslados de los eclesiásticos. Responsabilizó a los prepósitos de la economía parroquial sin tener acceso libre y directo a las finanzas de comunidad. Introdujo reglas civiles de elección de los prepósitos y los síndicos de la parroquia. Distribuyó las obligaciones entre el prepósito y la directiva civil de la parroquia para la manutención de la iglesia y las edificaciones parroquiales, para el buen funcionamiento de la escuela de los niños católicos (y solamente para ellos) y de la buena administración de la economía y las finanzas parroquiales. Incorporó al reglamento la obligación para los síndicos de entregar un informe final a la comunidad sobre los ingresos, gastos y el estado actual de todas las propiedades parroquiales al terminar los tres años de servicio.

\section{Postscriptum del reglamento}

Se dice en primer lugar dónde debe ser guardado el original del reglamento $y$, segundo, se indica que debe ser entregada una copia auténtica de éste a la Iglesia Romana de San Petersburgo para su estricto cumplimiento. La supervisión pertenecía al Colegio de Justicia para asuntos de provincias Liflandia, Estlandia y Finlandia (a quien ya competía la supervisión de la iglesia luterana).

\section{La suerte del documento}

El 12 de febrero 1769 fue publicado el reglamento para la comunidad de la iglesia Santa Ekaterina de Alejandría en San Petersburgo, como ley imperial dada tanto al clero como a los parroquianos con el objetivo de regularizar el funcionamiento económico de la parroquia y la predicación entendible por todos los parroquianos de diferentes idiomas. Las normas del reglamento fueron traspasadas a la comunidad de Moscú y luego, a las colonias de la cuenca del Volga. En el reglamento Ekaterina II declaró que no quiere intervenir en los asuntos de la fe. Entre los principales ítems consagrados en el documento estaba el control de los bienes por la comunidad que evitaba el manejo unilateral de los bienes parroquiales por el párroco. La comunicación con Roma fue permitida solamente para cuestiones espirituales.

En el mismo día de 12 de febrero en 1769 la monarca entregó a los feligreses de la iglesia La Carta Magna de donación de los derechos a los bienes de la iglesia, donde se confirmaba la propiedad perpetua del terreno parroquial para construcción de la iglesia, el edificio de la iglesia y otras edificaciones en este terreno: "para que nadie pueda pretender reclamar lo que pertenece a los parroquianos". El edificio 
de la iglesia, todas edificaciones parroquiales y casas sacerdotales se liberaron de los impuestos municipales y policiales, con la única obligación de mantener en buen estado el pavimento de calzada de piedra y limpieza de calle y del patio de la iglesia ${ }^{14}$.

Esto produjo grandes discrepancias con Roma por muchos años. Ekaterina negó el derecho de la curia romana a asignar los sacerdotes y controlar los bienes de los católicos en Rusia. La Santa Sede no reconoció la legitimidad del reglamento porque, entre otras razones, minaba la autoridad de Roma, invitando a la participación de los parroquianos a la responsabilidad de los negocios de la comunidad. Sin embargo, en los años siguientes, a pesar de los intentos romanos para obligar a la emperatriz a suavizar las medidas, el reglamento de 1769 fue aplicado en la práctica y sobrevivió hasta el concordato establecido entre Rusia y Roma en 1847.

El año 1772 Bielorrusia Oriental fue arrancada a Polonia. Esto significó que la cantidad de católicos en el imperio aumentara en 100.000 creyentes más 800.000 católicos de rito griego, los uniatas. Esto hizo necesario algunos cambios en el reglamento y nuevas intervenciones legislativas de Ekaterina II: i) la nueva versión excluía el llamado de los pastores desde Roma y todas las reglas de los trámites en el Colegio de Justicia y en el Colegio de Relaciones Internacionales, porque entre los nuevos ciudadanos rusos había suficiente cantidad de clérigos para satisfacer el servicio religioso; ii) la emperatriz por su propia autoridad nombró el obispo católico romano, un ciudadano ruso, y le entregó la administración del obispado más grande del mundo, desde Alaska hasta Polonia, bajo la supervisión del gobierno; iii) la Iglesia Uniata de Bielorrusia con los 800 mil greco católicos, recibió la legislación de su existencia similar a la de la Católica romana y fue entregada a la administración del arzobispo Uniata - un ciudadano ruso bajo la supervisión del gobierno-; iv) a la Santa Sede se quedó solamente la dirección espiritual a los creyentes de ambas comunidades.

Para el conde D.A. Tolstoi (1823-1889) el reconocido historiador ortodoxo, Ober, procurador del Santo Sínodo, ministro de Educación y presidente de Academia en Ciencias ${ }^{15}$, la política de Ekaterina II fue una presentación de la sabia decisión del control estatal sobre la colectividad católica en Rusia, defendida del despotismo de sus eclesiásticos.

Del punto de vista de P. Pierling S.J. (1840-1922), descendiente de los Pierling de Baviera, unos de primeros parroquianos de la iglesia Santa Ekaterina de Alejandría de San Petersburgo, sacerdote católico e historiador ruso ${ }^{16}$, esa medida fue no más que un ejemplo de arbitrariedad de las autoridades rusas que quitaba a Roma el derecho asignar los sacerdotes.

${ }^{14}$ Bulavina, M. A., cit. (n. 5), p. 37.

${ }_{15}$ Толстой, Димитрий, Римский католищизм в России. Историческое исследование. (Санкт Петербург, 1876). стр.178-179. TоLstol, Dimitri, Catolicismo romano en Rusia: Investigación histórica (San Petersburgo, 1876), pp.178-179. Traducción libre del título ruso por la autora.

${ }^{16}$ Pierling, Paul, La Russie et le Saint Siege (Paris, 1912), V, p. 16. 


\author{
Anexo 1 \\ Reglamento imperial DAdO a las Iglesias Romanas EXISTENTES EN RUSia POR \\ EKATERINA II, EL 12 DE FEBRERO 1769 \\ Traducción libre al español de \\ Yulia Poliakova \\ Universidad Técnica Federico Santa María, Valparaíso, Chile** \\ Redacción de Javier H. Ossa Valenzuela SJ***
}

Reglamento imperial Dado a las Iglesias Romanas eXistentes EN Rusia ${ }^{17}$

\author{
Por la gracia Divina \\ Nos
}

Ekaterina II

La emperatriz y autócrata de toda Rusia, etc. ${ }^{18}$

Ya hace muchos años, nuestros ascendientes, que descansan con Dios, dieron el permiso a nuestro imperio para que los clérigos de Iglesia Romana realizaran libremente su servicio religioso a los católicos que residen en el Estado nuestro.

Por orden de Su Majestad el emperador Pedro I el Grande, fue emitido un decreto del Sínodo ${ }^{19}$ y confirmado mucho después, por un Manifiesto al pueblo de la emperatriz Anna Ivánovna el 22 de febrero 1735, indicando un lugar determinado para construir en San Petersburgo una Iglesia Romana. Según dicha libertad benevolente de nuestros ancestros, fue construida en San Petersburgo, por los mismos parroquianos de religión romana, una pequeña iglesia de piedra. Para terminar la construcción de otra más grande se necesita mucha contribución de parte de los parroquianos, que pertenecen a cuatro naciones; asimismo falta establecer leyes civiles para llegar a un acuerdo recíproco sobre cuidado y mantención que ella exija, lo que hasta ahora no tiene lugar; así es como fue entregada a Nosotros por parte de los mismos parroquianos una petición con el siguiente contenido:

Primero. Que según las licencias designadas a ellos aquí, pudieran pedir a la congregación, como su institución superior espiritual en Roma, contratar para San Petersburgo clérigos extranjeros de buen nivel, con conocimiento de los idiomas propios de los feligreses, provechosos y eficientes para servicio en Rusia.

Segundo. Que pudieran siempre elegir, ellos mismos, al partir un prepósito $\mathrm{u}$ otro clérigo, otro sacerdote para su reemplazo entre los que se encuentren en San Petersburgo, que sea más experimentado y de mayores méritos, sin importar

**yulia.poliakova@usm.cl

*** jossasj@gmail.com

17 Traducción libre del título original.

18 Seguimos formato de reprint del documento de segunda mitad del siglo XVIII. Ver Anexo 2.

19 Una especie de Ministerio de Asuntos Religiosos a cargo de un representante personal del emperador. 
su nación, porque los feligreses siempre saben mejor que los de la congregación apreciar al elegido en su justo valor. Que el elegido para el servicio religioso fuera confirmado en su puesto por la congregación.

Tercero. Que los parroquianos puedan elegir entre sí los síndicos de la iglesia, los que junto con el prepósito tengan el poder pleno de mantener la iglesia y de aumentar los ingresos con las colectas recogidas de los feligreses y el alquiler de las edificaciones anexas para sostener la escuela parroquial y para otros gastos de la iglesia.

Con las deudas contraídas unánimemente por los parroquianos, ellos mismos se comprometen [a pagarlas] y de esta forma piden que no sea aceptado, como antes, que los prepósitos tomen préstamos en dinero con su firma personal, sin avisar ni pedir permiso a toda la comunidad parroquial y sin rendir las cuentas al abandonar el país, dejando la carga de pago sobre los feligreses.

La congregación hasta hoy día, después de muchos años de quejas no ha permitido hacer cambios a ninguno de los tres puntos anteriores, peor aún, a través de los enviados, los prepósitos confirmaron la situación sin efectuar cambios. En consecuencias los clérigos enviados para las cuatro naciones saben solamente un idioma, italiano, siendo así inútiles para las otras tres partes de la comunidad, por ser un pequeño grupo de italianos residentes; pero, los alemanes, franceses y polacos -sobre todo en Cronstadt, Riga y Revel ${ }^{20}$ - tienen necesidad de clérigos alemanes. Hay que indicar que los prepósitos religiosos enviados a ellos desde el extranjero desconocen las leyes, costumbres y particularidades del lugar. Sin embargo los experimentados padres alemanes que trabajaron aquí muchos años, no fueron respetados por sus méritos y, por decretos injustos, fueron llamados a Roma. Eso ha provocado a menudo descontentos entre los feligreses. Por último, agregan, los prepósitos traen un poder tan grande de Roma que afirman, ellos mismos, que todo lo que pertenece a la iglesia y lo que está dentro es propiedad de la Iglesia Romana y, por lo tanto, les está dada el uso y gozo pleno; aunque ellos nunca, ni antes ni ahora, tuvieron participación en las edificaciones que, con muchas dificultades, levantaron los parroquianos; que con sus propios medios, sin ayuda ninguna a su costo adquirieron. Por lo tanto humildemente han recurrido a Nos para que los parroquianos, ya favorecidos antiguamente con los mandatos para ejercer las libertades eclesiásticas, sean defendidos y que por clemencia se establezca una ley con la legítimamente pudieren administrar las rentas parroquiales.

Esas son las razones que Nos motivaron a investigar con precisión todas las quejas de los parroquianos romanos. Nos descubrimos que existe efectivamente una discordancia entre ellos y los clérigos, no solamente por la ausencia en dicha iglesia de reglas de responsabilidad mutua en ingresos y gastos de la renta, sino que hasta ahora tampoco existe una instancia jurídica en Nuestras instituciones gubernamentales donde ellos, en caso de disconformidad entre los feligreses y sacerdotes extranjeros, pudieren apelar para obtener juicio y castigo. Estando esta iglesia romana, excepto los dogmas de fe, bajo nuestras leyes civiles y habiendo sido construida y mantenida por cuenta de los parroquianos, Nos condescendemos a

${ }^{20}$ Bases militares de la costa báltica desde la época de Pedro I el Grande. 
la petición de Nuestros súbditos y con benevolencia decretamos para dicha Iglesia Romana en San Petersburgo el siguiente reglamento.

\section{Capítulo Primero}

Sobre los pastores de la Iglesia Romana en general

1. Los parroquianos residentes en la ciudad San Petersburgo son de cuatro naciones: alemanes, franceses, italianos y polacos; por eso los pastores de esta religión deben saber las lenguas alemán, francés, italiano y polaco, o por lo menos más de una de ellas.

2. Al prepósito o jefe y sus acompañantes llamarse y ser llamados padres o curas de almas y no misioneros, porque ellos vinieron para hacer servicio de su fe según los privilegios dados por Nos y Nuestros ancestros, que les permitieron venir a Rusia con este fin y no para ninguna propaganda de una nueva fe, lo que, por el decreto de nuestro Sínodo 22 de febrero 1724, fue proclamado a los padres y feligreses de esta iglesia.

3. Aunque por el mismo decreto no fue permitido tener en la iglesia más de cuatro clérigos, con uno de ellos como prepósito - dado que, en comparación con tiempos pasados, ha aumentado notablemente la cantidad de los residentes católicos, tanto en la ciudad como en los otros lugares a donde estos clérigos deben ser enviados- Nos benevolentemente permitimos mantener en esta Iglesia Romana en San Petersburgo dos clérigos más, incluyendo al prepósito.

4. Como fue ordenado en los decretos anteriores, ahora confirmamos una mayor cantidad de clérigos de la orden religiosa -que es la orden franciscana y de ninguna otra- para que sirva en esta iglesia. Y de éstos el prepósito tiene que enviar algunos para servicios religiosos a Cronstadt, Yamburg, Riga y Revel, como ya se dijo en los decretos anteriores.

5. Aunque antes fue ordenado que el tiempo de servicio en esta iglesia fuera no más de cuatro años, Nos benevolentemente les permitimos -si los parroquianos están contentos y los clérigos lo desean- quedarse por otros cuatro años, de acuerdo con los parroquianos. Todo esto para que el cambio de todos los clérigos no signifique para los feligreses muchos gastos ni tener que llamar nuevos y despedir a los que vivieren en buenas relaciones con ellos.

\section{Capítulo Segundo \\ Relativo al padre superior o prepósito en particular}

6. Se permite a los parroquianos, como fundadores de esta iglesia elegir, por acuerdo entre ellos, un prepósito entre los seis sacerdotes que se encuentran en ella, según sus méritos. La forma cómo hacer las elecciones será descrita en el siguiente capítulo.

7. Este prepósito debe velar que se siga, en las reglas de la economía parroquial, Nuestro reglamento en todo sin cambio ninguno.

8. Él mismo tiene que velar para que entre los pastores romanos en San Peters- 
burgo, en Liflandia ${ }^{21}$ y sobre todo en Riga, en Ingermanlandia ${ }^{22}$ y en Estlandia $^{23}$ no haya más cantidad de la mencionada orden franciscana. En el caso que, sin un decreto especial, aparezcan más, debe informar obligatoriamente sobre este asunto a Nuestro Colegio de Justicia de Liflandia. Excluyendo sin embargo los padres en servicio personal de los ministros extranjeros y aquéllos de los barcos mercantes que prestan servicio espiritual mientras los dichos barcos estén en aguas rusas.

9. El prepósito debe evitar, que sin su permiso y el de la comunidad, los mencionados pastores visitantes se inmiscuyan en los asuntos de la iglesia y provoquen problema. Además está prohibido al prepósito y a los pastores tratar de convertir a los cristianos de Rusia; lo que ya antes, el 22 de junio del año 1763, fue declarado por Nos.

\section{Capítulo Tercero}

Relativo al llamado de los pastores, de su juramento e incorporación a la Iglesia Romana destinada

10. Cuando en la iglesia aparece una vacante para un padre, en esta ocasión el prepósito junto con los síndicos debe informar al Colegio de Justicia de Liflandia, Estlandia, y Finlandia, como lugar de sus asuntos jurídicos, de lo que más adelante en el capítulo octavo será indicado en particular. Este Colegio a su vez informará sobre dicha petición al Colegio de Relaciones Exteriores para llamar al reemplazante y actuar como corresponde según Nuestro decreto sobre esta materia del 6 de noviembre de 1766.

11. El padre recién llegado debe presentarse con su diploma legítimo al Colegio de Justicia.

12. El prepósito recibirá en el Colegio de Justicia al nuevo padre destinado a la iglesia y lo llevará al secretario designado del Colegio para tomar su juramento, según las normas del derecho canónico romano. Un ejemplar impreso del juramento con la firma del que jura debe permanecer en el Colegio de Justicia, luego, el prepósito debe determinar su puesto e introducirlo en él según el rito de la fe romana.

\section{Capítulo Cuarto}

De la elección e instalación del prepósito en San Petersburgo

13. Al dejar el puesto el prepósito de iglesia, por diversas razones, los otros padres junto con los síndicos deberán informar inmediatamente al Colegio de Justicia.

14. El Colegio indicará el día de elecciones del nuevo prepósito de la iglesia, en acuerdo con los otros padres y con los síndicos. Se excluyen [de votar]

\footnotetext{
${ }^{21}$ Liflandia, territorio sobre la costa báltica, que incluía parcialmente actuales Letonia y Estonia.

${ }^{22}$ Ingria, territorio entre San Petersburgo y Finlandia

${ }^{23}$ Estonia.
} 
los viajeros o residentes contratados temporalmente para Nuestro servicio. A éstos les está prohibido estrictamente entrometerse de cualquier manera en los asuntos de la iglesia y dar de su parte alguna propuesta al respecto ya que, antes, ha producido mucha confusión entre los parroquianos.

15. En el día indicado, y en presencia de un oficial del Colegio y su secretario, reunidos todos los parroquianos, excluyendo los que por razones legítimas no pudieren asistir y se hubieren disculpado por escrito, después de la misa y la prédica correspondiente al caso, el secretario del Colegio debe leer el edicto del permiso para elegir y asignar a la comunidad al nuevo prepósito de entre los padres adscritos a la iglesia.

16. Cada nación ira eligiendo al prepósito respetuosamente, aparte y por turno. En presencia de todos los síndicos, el secretario registrará los votos orales y por escrito ${ }^{24}$. En caso de desacuerdo, se designará el que obtuvo más votos; y, si la votación no se termina en un día, se aplazará para el día siguiente.

17. Al terminar las elecciones el secretario, en presencia de un oficial del Colegio, proclamará a todos los parroquianos el nuevo prepósito; por esta declaración el nuevo prepósito realmente obtiene su título y ocupa su cargo.

18. El recién elegido prepósito, sin salir de la iglesia, deberá firmar y entregar al miembro del Colegio de Justicia un documento por el cual se compromete a cumplir Nuestro reglamento con máxima responsabilidad en todas sus partes. Este documento será guardado con los otros documentos relativos a las elecciones en el Colegio.

19. El Colegio de Justicia, sin perder tiempo, deberá exigir del Colegio de Relaciones Exteriores promover donde corresponda la confirmación eclesiástica del nuevo prepósito, elegido en acuerdo mutuo por los parroquianos de la Iglesia Romana en San Petersburgo y designado por ellos como padre prepósito de esta iglesia en su rango y puesto.

20. A Nosotros llegaron muchas quejas de parte de los parroquianos respecto del prepósito actual, sin embargo Nos piden no excluir al prepósito actual de la lista de los candidatos. En el caso que él reciba mayor cantidad de votos, permanecerá como prepósito según este reglamento. Si los parroquianos no lo reeligen, será despedido y el nuevo prepósito será el elegido por los parroquianos de la iglesia. Al ex prepósito se le restituirá al lugar desde donde llegó a Rusia.

\section{Capítulo Quinto}

De los síndicos de la iglesia

21. Del mismo modo, el Colegio debe asignar un día para la elección de los síndicos de la iglesia, por acuerdo entre los parroquianos.

22. De las cuatro naciones deberán ser elegidos dos síndicos de cada una, para que

${ }^{24}$ En el documento ruso y su variante en latín no está claro si la votación individual es por escrito o sólo oral. 
la administración de la iglesia no se detenga en el caso de ausencia temporal o enfermedad de uno de ellos.

23. Cada nación debe presentar cuatro candidatos para la elección.

24. En el día indicado, cada nación en presencia de un oficial del Colegio de Justicia y su pastor, quien tiene que hablarles llamando a la concordia y el silencio, elegirá por la mayoría de votos dos síndicos de la iglesia; un secretario del Colegio toma las notas protocolares. Según los resultados de la elección, el Colegio confirma los elegidos, basándose en Nuestro reglamento.

25. Los síndicos son ayudantes del prepósito en asuntos económicos de la iglesia y deben actuar como representantes de todos los parroquianos, desempeñándose en su puesto durante tres años.

\section{Capítulo SeXto}

Sobre los ingresos de la iglesia ${ }^{25}$ y las obligaciones de los síndicos

26. Todos los ingresos que manejan el prepósito y los síndicos, deben ser respetados como pertenecientes a la misma iglesia romana y no a las personas eclesiásticas. Los ingresos son como sigue:

27. Primero. Las casas de propiedad parroquial y el dinero recibido anualmente en la caja común por su arriendo. Segundo. Ingresos legítimos por servicio espiritual y donaciones. Tercero. Dinero recibido de los feligreses y otras limosnas de afuera para la iglesia, a veces llamado stola como: por bautizos, matrimonios, funerales y otros servicios religiosos (excluyendo lo que los mismos feligreses entregaron al sacerdote para él personalmente y no para la iglesia), además de otros dineros recogidos por los domingos y días feriados. Cuarto. Aportes enviados de otros países y ciudades extranjeras para edificación parroquial, o ingresos de otros benefactores.

28. De estos ingresos se debe mantener a los sacerdotes según su cargo y abastecerlos de todo lo que sea necesario para una vida de buena calidad.

29. Los síndicos, desde el comienzo de sus servicios, deben preocuparse en examinar el estado actual de la iglesia y hacer una lista detallada de todas las edificaciones y espacios parroquiales, revisar si coinciden en todo con los documentos existentes y que no haya algunos destrozos o faltas producidas por alguien. También deben revisar y anotar el estado y la firmeza del edificio $^{26}$, de las casas de los sacerdotes, de todos los vasos sagrados, casullas, libros y alhajas de la iglesia y otras cosas de valor.

30. En el mismo inventario anotar todo el dinero parroquial presente, débitos y créditos y si hay en custodia objetos ajenos, para que la nueva administración pueda ponerlo en el inventario inicial y luego manejar los recursos materiales como corresponde.

31. Dicho inventario con todos los documentos eclesiásticos, contratos, obligaciones y otras cartas, igual que el dinero parroquial y los ingresos casuales,

\footnotetext{
${ }^{25}$ En original ruso Ekaterina ocupa el término Kirja.

${ }^{26} \mathrm{La}$ comunidad construyó unos edificios para arriendo y con ese dinero se estaba construyendo una iglesia más grande en tiempos de este documento.
} 
deben guardarlos y mantenerlos en un baúl cerrado, bajo timbres del prepósito y de todos los síndicos y deben vigilar que nadie, sin el permiso de ellos, pudiere abrirlo y sacar algo de allí.

32. Documentos, obligaciones y contratos se deben examinar y en el caso de aparecer algunas dudas y discusiones, estas deben ser estudiadas y resueltas jurídicamente; los tramites en juzgados para los asuntos parroquiales, tienen que hacerlos los síndicos, por acuerdo entre ellos, para que el prepósito, a cuyo servicio y ayuda se encuentra, no se distraiga de su dedicación a las labores espirituales.

33. Los mismos síndicos tienen que preocuparse de continuar la edificación ya empezada con conocimiento y consentimiento del prepósito. Los gastos para ello deben distribuirlos con moderación y cálculo para que las deudas reconocidas por los feligreses de cuyas moras puedan sufrir los comerciantes lugareños sean pagados, lo más rápido posible, de los ingresos parroquiales.

34. El dinero recogido a favor del tesoro público de la iglesia deberá ser respetado como propiedad de todos los feligreses y puede ser ocupado según su voluntad y deseo. Esto siempre estará bajo la protección de Nuestras leyes.

35. Los parroquianos deben preocuparse siempre que la iglesia y todo lo que le pertenece esté en buen estado, si algo se deteriora debe ser reparado según las posibilidades.

36. Benévolamente permitimos al prepósito, a los síndicos y a todos los feligreses, fundar una escuela de la iglesia de la mejor forma, para que los jóvenes del rito Católico Romano y ningún otro, puedan estudiar dignamente las ciencias.

37. El prepósito y los síndicos pueden ocupar para edificación la ofrenda colecta, también el dinero por servicios espirituales y donaciones. Asimismo, deben firmar los contratos y obligaciones y los síndicos deben preocuparse de inscribirlos en la forma correcta en los lugares correspondientes, es decir en oficinas especializadas o en la policía.

38. La recolección diaria de pequeñas cantidades, según el caso, puede ser recogida por el prepósito sólo anotando la cantidad. Los síndicos, a su vez, por lo menos cada tres meses, tienen que controlar este dinero y revisar su cantidad con atención, comparándolo con los apuntes hechos por el prepósito, para luego inscribir dicha cantidad en el libro parroquial.

\section{CAPítulo SÉPTimo}

De los informes finales y la desvinculación de los síndicos

39. Después de tres años en su cargo, los síndicos deben entregar un informe final de los ingresos, gastos y el estado actual de todas las propiedades parroquiales a la comunidad y confirmarlo con comprobantes para que los feligreses puedan ver el estado de los gastos parroquiales y la calidad de gestión administrativa de la economía.

40. Para revisar las cuentas los parroquianos pueden elegir una comisión e incorporar allí un contador profesional que revise todas las cuentas de in- 
gresos y gastos, tanto en dinero, como en materiales y objetos, haciendo sus observaciones, ante las cuales los síndicos tienen que dar claras explicaciones.

41. Después de la auditoría positiva, los síndicos pueden desvincularse y si los parroquianos no logran persuadirlos de quedarse en su cargo para otro tiempo, la decisión quedará a voluntad de los síndicos.

42. Si los síndicos declaran su decisión de no aceptar la propuesta de proseguir, luego de las elecciones y cuando los nuevos síndicos tomen posesión de sus cargos, se despedirá a los antiguos con agradecimiento público y un certificado que indique que cumplieron bien y honestamente su labor y que se preocuparon por la prosperidad parroquial, firmado por el prepósito y los parroquianos.

\section{Capítulo Octavo}

Sobre el juzgado bajo cuya jurisdicción debe encontrarse la iglesia del credo romano

43. Hasta ahora las existentes discordancias entre los feligreses y los sacerdotes del rito romano tenían lugar solamente por ausencia de leyes establecidas para resolver los problemas de administración de la economía parroquial y por cuanto no existían las reglas cuyo cumplimiento debiese ser obligatorio, ni tampoco fueron definidas las partes en discusión y el tribunal donde pudiesen buscar justicia y defensa para sí, o ayuda rápida para obtener una solución.

44. Para todas las disputas que puedan surgir en el futuro entre el clero y los parroquianos del culto romano, o entre los síndicos y los parroquianos por los problemas económicos de la iglesia, Nuestra voluntad altísima es entregar esta facultad al Colegio de Justicia de los asuntos de Liflandia, Estlandia y Finlandia. Ya que allí mismo solucionan los extranjeros de otras religiones cristianas los asuntos económicos de sus iglesias, allí es donde se solucionarán las pugnas y los desacuerdos de las mencionadas disputas de la iglesia romana según el dicho reglamento con la máxima rapidez, evitando todas las demoras judiciales.

45. Porque según Nuestras leyes y las de Nuestros ancestros, a los residentes del rito romano en nuestro imperio se les ha permitido confesar su religión libremente durante muchos años, el Colegio de Justicia, durante el proceso de investigación de las disputas en administración eclesiástica no deben, por ningún motivo, intervenir en los dogmas de la misma religión romana.

\section{Capítulo Noveno}

Sobre el despido de los sacerdotes

46. Previamente en el punto 5 del capítulo primero están indicados los años de servicio de los sacerdotes, del prepósito y de los síndicos: sin embargo al tratar de prolongar el servicio de ellos en el caso de buena labor es conve- 
niente mantenerlos contentos y abastecidos con todo lo necesario, así ellos no tendrán razones legítimas para hacer quejas.

47. Si uno de los padres no desea quedarse más tiempo, entonces, para traer uno nuevo hay que actuar como está ordenado en el capítulo tercero. Luego de la llegada, el juramento y la recepción del nuevo padre, entregar al saliente el certificado firmado por el prepósito y los síndicos en nombre de los parroquianos. Si el clérigo es dejado ir o despedido por la conducta, le corresponde el despido al Colegio de Justicia. El mismo Colegio debe tramitar un pasaporte en el Colegio de Relaciones Internacionales para la salida libre de Rusia al lugar donde quiera el interesado.

\section{Capítulo Décimo}

Sobre eclesiásticos inscritos en la Iglesia Romana en Moscú

48. La Iglesia Romana de Moscú, según las antiguas normas del Estado ruso, puede tener solamente un prefecto y otro sacerdote como su ayudante, los dos de la orden de los capuchinos; el Colegio de Justicia tiene que instalar en aquella iglesia una administración de economía como fue mencionado arriba, elegir uno o dos síndicos cuya tarea es velar por las propiedades parroquiales y supervisar las necesidades, entregando informes correspondientes a los parroquianos de la forma indicada arriba.

49. El prefecto capuchino de la Iglesia Católica de Moscú, aparte de su asistente actual puede recibir ayuda de otro, también un capuchino, si hay necesidad de hacer servicios religiosos a pedido ${ }^{27}$.

50. Dichos padres capuchinos en cuestiones que exigen justicia y castigo por desacuerdo entre el clero, síndicos y parroquianos, deben presentarse en el Colegio de Justicia de Liflandia como lugar de solución de sus asuntos jurídicos, el cual debe participar en las elecciones de los síndicos, en el llamado a los sacerdotes y en otras tareas, de la misma forma como fue indicado arriba para la Iglesia Romana en San Petersburgo.

\section{CAPÍTUlo UndÉCIMO}

Sobre asignación los clérigos para los colonos de la religión romana

51. Relativo a la asignación de clérigos para los colonos: se realizará el llamado a los padres de la misma orden franciscana que ya está presente allí, de acuerdo a las demandas de Nuestro Departamento de Protección y Custodia. Cuando estos lleguen, por solicitud del Departamento, el representante del Colegio de Justicia debe acompañarlos a la iglesia asignada para su servicio, luego de presentar el juramento canónico les entregan el permiso para ocupar su cargo sacerdotal de parte del Colegio de Justicia. En todos los asuntos, ellos están bajo la dirección del mencionado Departamento de Protección y Custodia,

${ }^{27}$ Como, por ejemplo, residentes extranjeros ricos que pedían servicios sacramentales o litúrgicos en sus residencias campestres. 
el que en casos confusos debería tener contacto directo con el Colegio de Justicia.

\section{POSTSCRIPTUM}

Este reglamento debe ser guardado en su forma original en Nuestro Colegio de Justicia de asuntos de Liflandia, Estlandia y Finlandia; el Colegio tiene que entregar una copia auténtica de éste a la Iglesia Romana de San Petersburgo para su estricto cumplimiento.

Anexo 2.

28

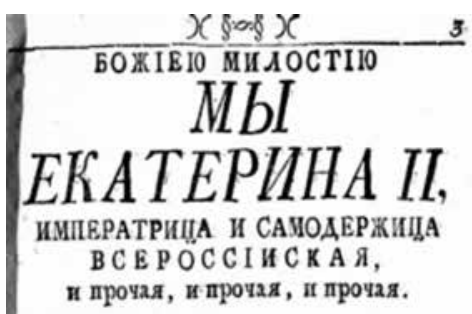

$\mathrm{O}^{\mathrm{T}} \mathrm{s}$

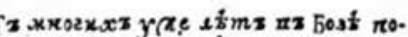

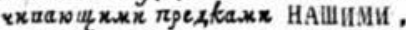

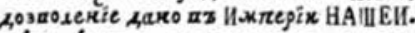

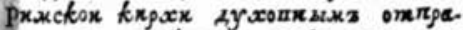

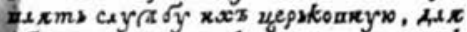

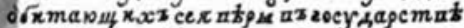

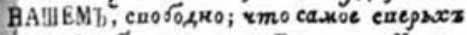
тереане биншкхз по Государл Ижле. gainuja IIs ГPA Bestkkazo ronestain orz.

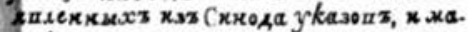

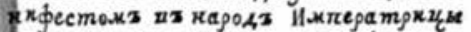

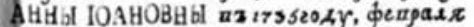

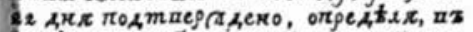
carkmremegorpat $n$ atemo ocosinate Lis mor yegikan. Ilo makozox omx

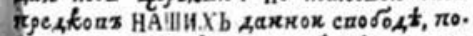

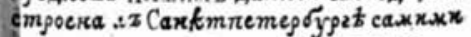

$a$ $\pi \rho x \times 0$.

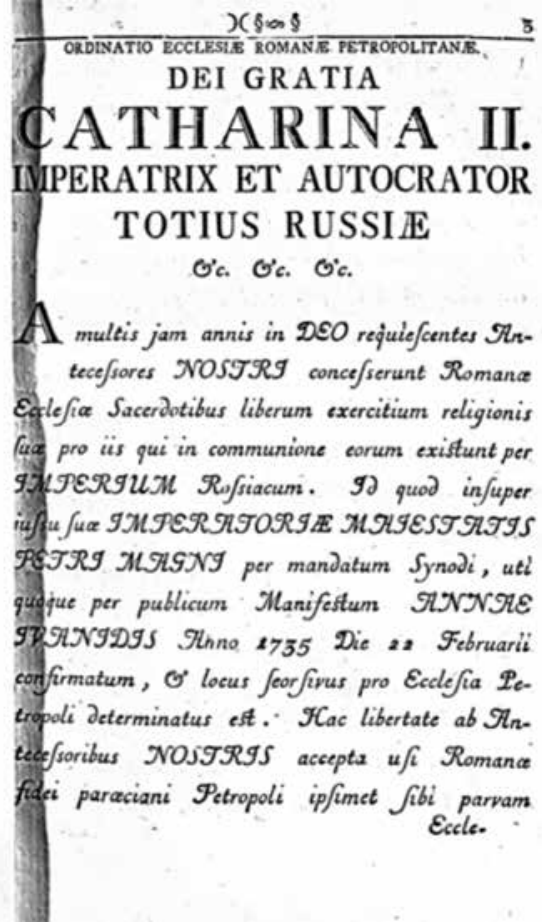

Las primeras páginas del Reglamento en ruso y latín de reprint a fines del siglo XVIII. 
29

\section{Anexo 3.}

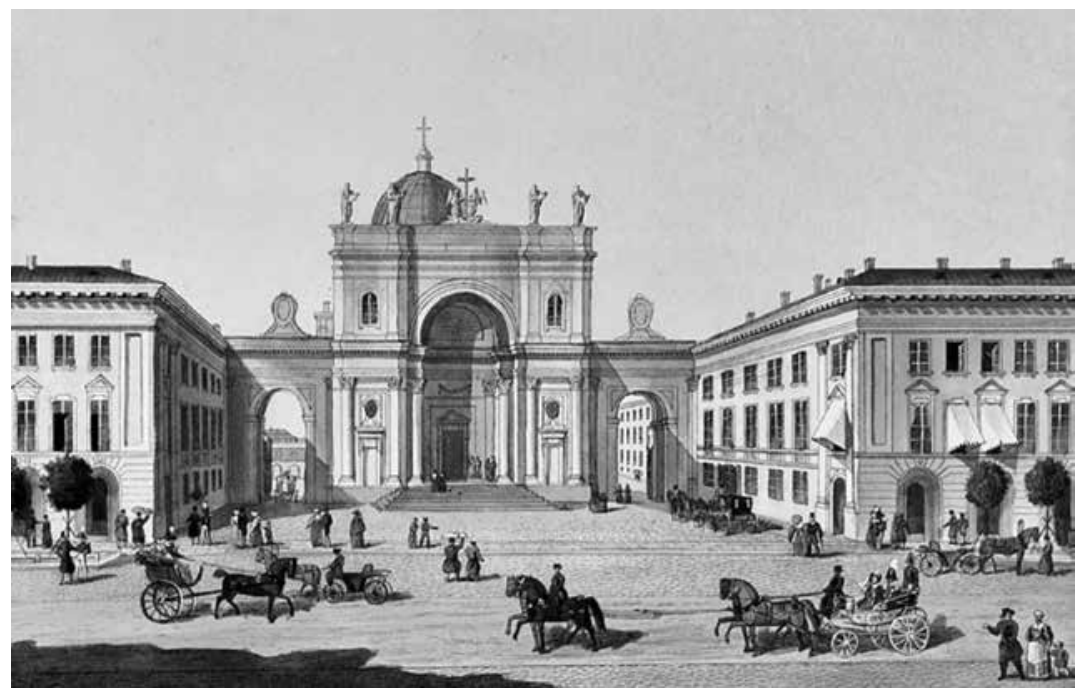

San Petersburgo comienzo s. XIX. Iglesia católica Santa Ekaterina de Alejandría

${ }^{29}$ Litografía de Karl Beggrov (1799-1875), miembro de la Academia de Bellas Artes de San Petersburgo. Biblioteca municipal de Nancy. Francia http://www.flickr.com/photos/ bmnstanislas/10741912194/ 